\title{
ROOF LEAK DETECTION BY THERMOGRAPHY OF AS-BUILT BIM
}

\author{
D. Zahradník \\ ${ }^{1}$ CTU, Czech Technical University in Prague, Faculty of Civil Engineering, Department of Geomatics, Thákurova 7, Praha 6, \\ Czechia - david.zahradnik@fsv.cvut.cz
}

Commission V, WG V/7

KEY WORDS: BIM, thermography, mesh model, roof leakage and Image registration.

\begin{abstract}
:
The horizontal roofs of industrial buildings are the weakest part of a structure. Imperfect design of horizontal roofs causes roof leakage. For roofs with a large surface area, locating leakage points is very difficult. The problem is solved by aerial thermography using drones. Modern high-resolution thermal cameras make it possible to detect roof leaks. By processing the RGB camera and thermal camera data, a thermal mesh model is created for implementation into the BIM. Building information models are data managers throughout the life cycle of buildings. BIM helps prevent clashes, improve collaboration and record building information from IOT devices. For building maintenance, the results of thermography need to be implemented in BIM. BIM managers create a roof repair plan based on the severity of the roof leakage. This paper proposes a methodology to implement the results of roof leak detection, starting from data collection and continuing with the processing of geometric and thermographic data and finalizes with implementation.
\end{abstract}

\section{INTRODUCTION}

Roof leakage is created by holes in PVC foil. Water from rain falls on the roof and search the easiest way to drain away. Horizontal roofs are almost flat with low slope of 5 degrees, so water does not drain away fast. Small holes in PVC foil allow infiltration into roof structure. Water has no escape and while temperature is changing, water is changing its form and it causes problems like heat insulation degradation and corrosion. There are several solutions like visual inspection, electropulse test, needle test, smoke test. Mentioned tests are non-destructive method to detect hole in PVC foil. Testing is performed on a small area with radius around 0,5 meter. Advantage of this methods is precision localisation hole on small horizontal roof. Usage of these methods for large roof is overpriced. Roof leak detection with thermography represents solution for large horizontal roof with reasonable price.

There are many types of horizontal roofs. Basic division is deck, double deck or multi deck. Furthermore, horizontal roofs are divided with and without windy space. Roof leak detection can be done only on roof without windy space. PVC foil must lay on heat insulation, so radiant heat from moisture heat insulation can be spotted on TIR images. Windy space causes changes of temperature in roof structure, accordingly seen on TIR images. Thermography can also be used for investigation of historic buildings and structures. High contrast on TIR images must be seen for further analysis. High contract is capturable during cooling and heating phases. High contrast can cause various materials or presence of water in structure. (Solla et al., 2020) (Adamopoulos et al., 2020).

When area of interest is small, and TIR image covers all area. 2D homography, or projective transformation of image is a solution for integration to BIM. (Antón et al., 2021).

Radiant heat captured by TIR images consists of emitted and reflected heat radiation, which is eliminated by capturing data with specific angles, or daytime. Problem also solves pixel-bypixel rectification by calculation of atmospheric radiance. (Miño et al., 2021). Shadows are also problematic areas, reflected heat radiation is missing in shadows and part of building isn't properly heated for further thermography monitoring. Solution is to adjust temperature interval of thermal camera to remove the shadow effect by algorithm. (Huang, Shih, Hsu, Chiang, 2020).

Aerial 3D thermography is highly efficient for complex data collection of building. Single TIR image capture part of entire building, multiple TIR images can be proceeded by SfM algorithm for creation of 3D model entire building. (Daffara et al., 2020) (Dlesk et al., 2018).

TIR images have lower resolution quality than RGB images. Processing of TIR images by SfM algorithm requires high contrast of radiant heat and high overlap. High contrast of TIR images is hard to achieve on some structure or building therefore TIR images cannot proceed by SfM. Problem solves combination TIR and RGB images captured at the same time by one device. First step is to remove distortion on all images and then reproject TIR images onto RGB images by collinear transformation. (Dlesk et al., 2021).

Thermography is also used for condition monitoring of building interior. Temperature information is integrated into BIM model for monitoring thermal comfort levels over time to automatic change heating temperature or ventilation. (Natephra et al., 2017).

Model reconstruction directly by SfM from TIR images has low geometric quality for improvement it is better to use Terrestrial Laser Scanner (TLS) for capturing geometric data. (Macher et al., 2019) (Lagüela et al., Arias, 2014) BIM is created based on data from TLS. TIR images are processed by bundle adjustment and for façade thermal orthophoto is used geometric data from BIM. (Previtali et al., 2013) .

BIM-based energy analysis is improved by thermography inspection. TIR images are processed to thermal point cloud, 
where each point represents radiant heat. Information of radiant heat is mapped on meshed BIM, and it is converted into thermal resistance. Results are used in energy analysis. (Ham et al., 2015).

Next level of implementation thermography into BIM is creation or calibration of Building Energy Model (BEM) by thermography data. BEM helps for simulation heating energy efficient and prevent cash losses due to heating in winter. (Rakha et al., 2021) (Bayomi et al., 2021)

\subsection{Test object}

House of Culture in Kolin was used as a testing object. Its roof is horizontal and consists of load-bearing roof structures, heat insulation and upper PVC foil. Area of interested roof is 1160 $\mathrm{m} 2$, as it's seen in figure 1 . Roof is divided by roof slope into two sections with 4 outfalls, as its seen in figure 2 . Medium slope of horizontal roof is 1 - 3 degrees. Water from rains fall on the roof and flows to outfall using the shortest path. When a hole appears on waters way in PVC foil, water infiltrates into structure.

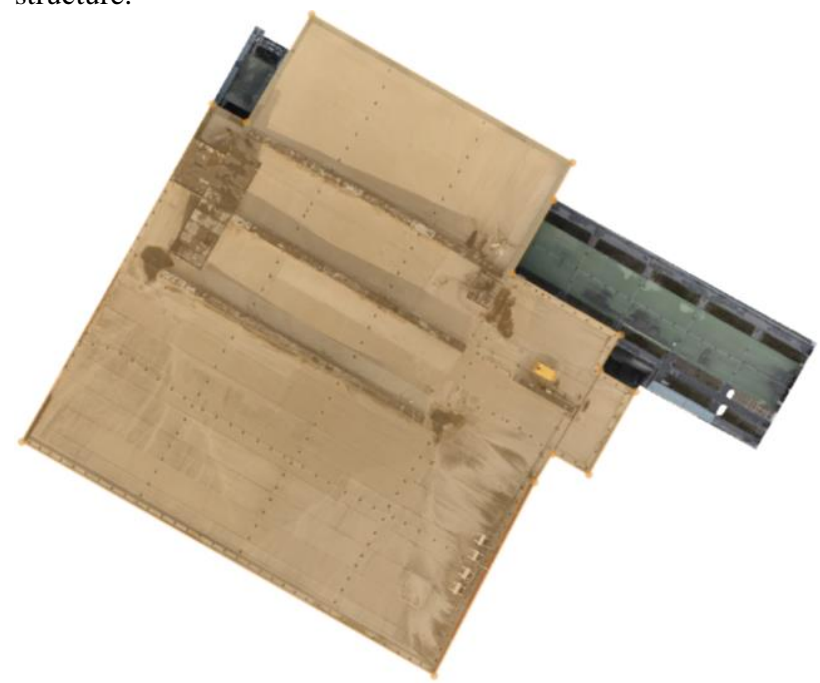

Figure 1. Horizontal roof (orange polygon)

Lightning conductor, air conditioning, transmitter and electricity backup are placed on roof. Thermal radiation can be expected near air conditioning and electricity backup, when device is in operation. TIR images will be affected by this thermal radiation.

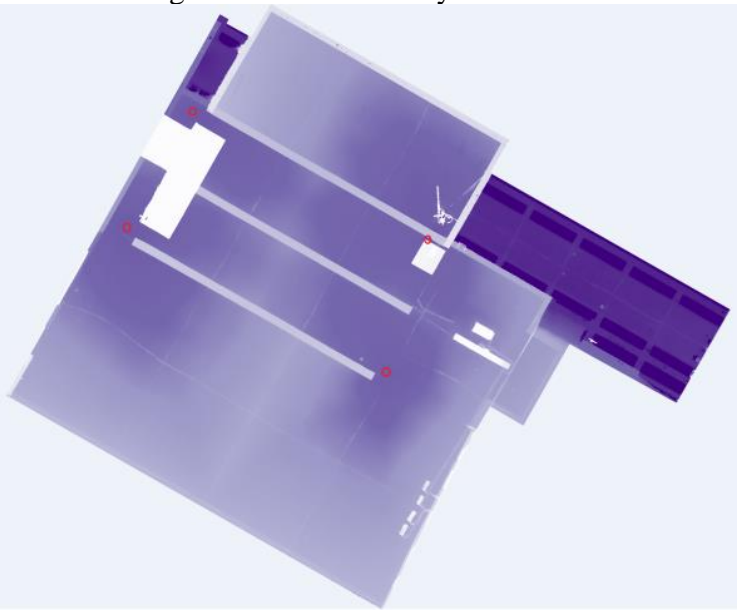

Figure 2. Visualization of roof slope with red marks of outfall

\section{MEASURMENT}

DJI drone with RGB and thermal camera was used for capturing data. DJI Mavic 2 Enterprise Advance Dual (DJI M2AE Dual) allows capturing RGB and TIR images simultaneously. RGB camera contains $1 / 2$ "CMOS sensor with 48 MP. Thermal camera has $640 \times 512$ resolution and 2 degrees temperature measurement accuracy.

Data was collected by flight mission; flight duration was 12 minutes, and it was without any complications. Parameters of flight mission are seen in Table 1.

\begin{tabular}{|l|c|}
\hline \multicolumn{2}{|c|}{ Flight parameters } \\
\hline Altitude & $20 \mathrm{~m}$ \\
Gimbal setup & NADIR \\
Frontal overlap & $90 \%$ \\
Side overlap & $90 \%$ \\
Flight velocity & $2 \mathrm{~m} / \mathrm{s}$ \\
\hline
\end{tabular}

Table 1. Flight parameters

During the flight mission count of RGB and TIR images was 244. Flight velocity was setup on minimum. High velocity causes image deformation on camera without mechanical shutter.

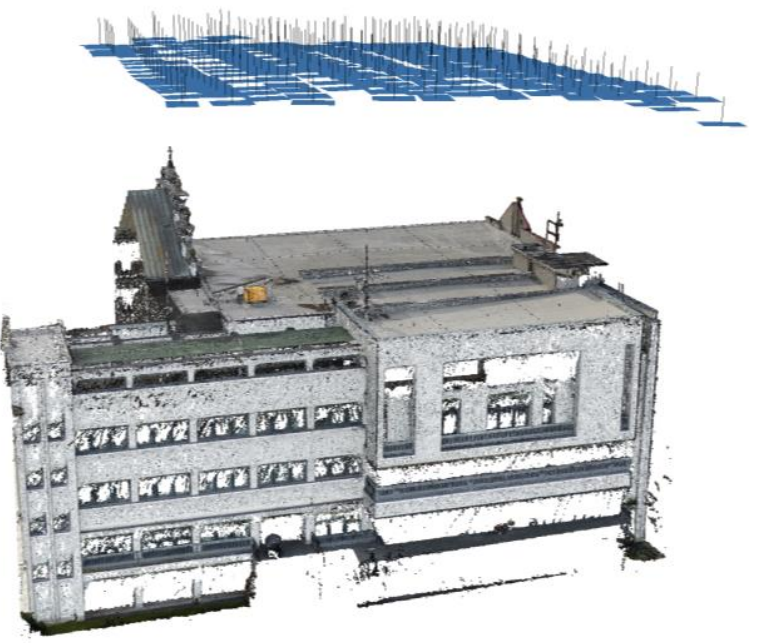

Figure 3. Image position with point cloud

RTK module allows allows to save position of images with centimetre accuracy, so count of ground control points can be minimized. In this project RTK module was used and ground control point was not used for time saving reason. Errors incurred by omitting GCPs didn't have any effect on purposes of this paper.

Data collection for roof leaking detection is dependent on weather condition. The reason is capturing the difference radiant heat given by heat insulation. Water under PVC foil is soaked in heat insulation, and it is changing its form while changing weather conditions. Difference between dry and humid heat insulation can be cached by temperature difference. Humid heat insulation has bigger heat capacity than dry. Humid heat insulation can be spotted after changing weather conditions, especially after sunrise or after sunset. Humid heat insulation stays colder after sunrise, or after sunset it stays 
warmer than dry heat insulation. Best season for data collection of roof leak detection is late spring, summer and autumn.

Due to the absence of publishable data from best season, it was measured in December with best possible weather conditions. Data was collected on $15^{\text {th }}$ December after $3 \mathrm{pm}$ after heating of roof by the sun.

\subsection{UAV RGB DATA}

RGB images are used for geometric purposes. High quality RGB images allow generation 3D model by Structure from Motion (SfM) method. DJI M2AE Dual allows export only jpeg format of RGB images. Weather condition must be considered before capturing data. Format jpeg is not editable without loss of image quality. It is better to capture data under the same conditions and avoid editing caused by sunshine.

For better geometric model it is recommended more RGB images from different angles. Easy way to improve geometric data is to and flight mission with gimbal setup GRID. Gimbal angel setup is between $45^{\circ}$ and $75^{\circ}$. Next step to improve geometric model is to add images façade captured like as roof.

\begin{tabular}{|l|c|}
\hline \multicolumn{2}{|c|}{ RGB camera } \\
\hline Sensor size & $1 / 2^{\prime \prime}$ \\
Megapixels & 48 \\
Focal length & $4,5 \mathrm{~mm}$ \\
$35 \mathrm{~mm}$ Equivalent & $24 \mathrm{~mm}$ \\
FOV & $84^{\circ}$ \\
Pixel size & $0.000811249 \mathrm{~mm}$ \\
Image width & $8000 \mathrm{px}$ \\
Image heigth & $6000 \mathrm{px}$ \\
\hline
\end{tabular}

Table 3. RGB camera parameters

\subsection{UAV THERMAL DATA}

TIR images contain information about radiant heat on a surface. Radiant heat spotted with thermal camera consists of the emission of the target object itself, the emission of the surroundings reflected by the object, and the emission of the atmosphere. Basic output format from thermal camera is RJPEG. Radiometric JPEG have temperature data embedded in each pixel. Temperature data consist of the whole range of radiant heat. Final image is edited in thermography software, all images are justified in same range for next image processing by SfM.

TIR images from DJI M2AE Dual allow export only in JPEG. Problems arise when temperature range is slightly changing during a flight. Format JPEG is not editable without losing image quality, so DJI M2AE Dual is not suitable for thermography mapping. Each TIR images have different thermal interval, and it can't be editted like RJPEG format. TIR image are processable by SfM, but results correspond with problem caused by JPEG format, each TIR image represent slightly different range of temperature.

Maximal radiant heat of roof is $30^{\circ}$ and minimal $10^{\circ}$, air temperature when data capture was $10^{\circ}$.

TIR camera - Uncooled Vox

\begin{tabular}{|l|c|}
\hline \multicolumn{2}{|c|}{ Microbolometer } \\
\hline & \\
Focal length & $9 \mathrm{~mm}$ \\
35 mm Equivalent & $38 \mathrm{~mm}$ \\
Pixel size & 0.0012 \\
Image width & $640 \mathrm{px}$ \\
Image height & $512 \mathrm{px}$ \\
\hline
\end{tabular}

Table 4. RGB camera parameters

\section{PROCESS DATA}

\subsection{Point cloud and ortomosaic}

RGB and TIR dataset was processed by Structure from Motion method in Agisoft Metashape 1.7 (Agisoft LCC, St. Petersburg, Russia). Each dataset was processed independently. High side and frontal overlap allow process of TIR images. High radiant heat contrast must be visible on TIR images to allow process of TIR images as RGB images. When TIR images don't contain high radiant heat contrast and it doesn't process by own. It is recommended to use combination RGB and TIR images (Dlesk et al., 2018) (Dlesk et al., 2021).

First step of process is alignment of picture and tie points detection, the "High" accuracy mode was set. Georeferencing of model was omitted for reason of using RTK module. Georeferencing precision is sufficient for roof leaks detection. Thus, the dense point cloud, DEM and ortomosaic was produced. DEM resolution comes out from dense point cloud, and it is $8 \mathrm{~mm} / \mathrm{px}$. DEM contain $5 \mathrm{~mm}$ size noise due to noncalibrated camera. Noise size correspond with Ground Sample distance (GSD) of images. Ortomosaic GSD is $5 \mathrm{~mm}$.

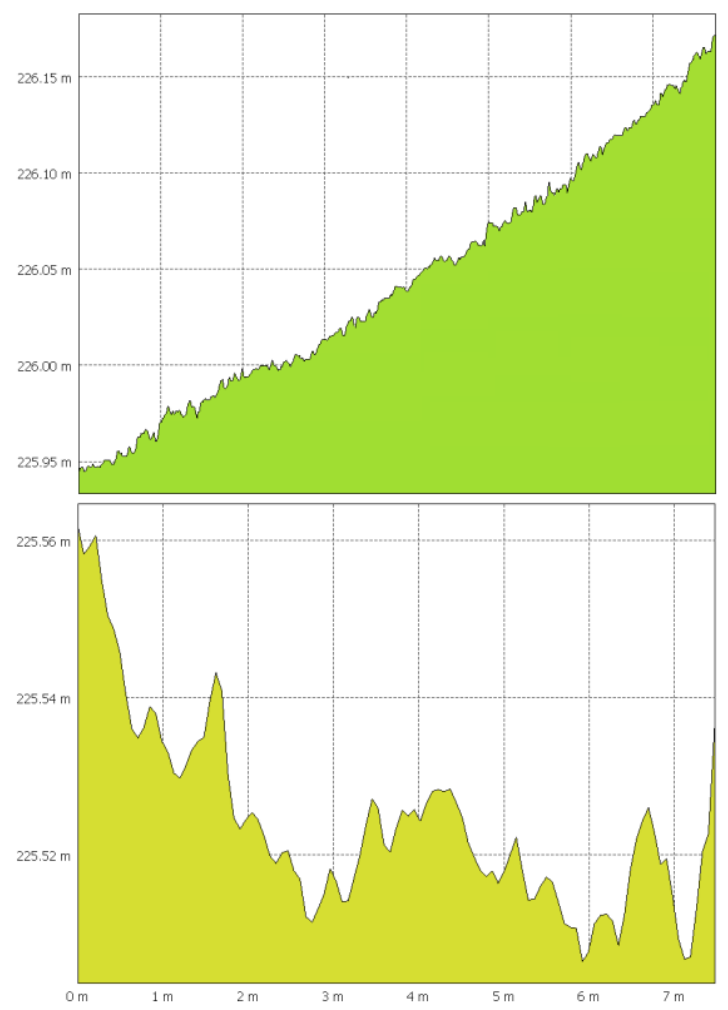

Figure 4. RGB DEM profile and TIR DEM profile

Process with TIR images is similar with small difference. First step of process is alignment of picture and tie points detection. If it is proceeded TIR images like RGB images, low quality of dense point cloud and DEM are expected, as it is seen in figure 
4. TIR images have lower image quality than RGB images, better solution is usage of geometric data computed by RGB images. RGB and TIR dataset alignment is itemized with control point evenly spaced on roof. RGB DEM is imported to TIR dataset, and ortomosaic is processed. TIR ortomosaic GSD is $2 \mathrm{~cm} / \mathrm{px}$.

\subsection{Roof leaks detection}

Roof leaks are detected by radiant heat on surface of horizontal roof. Roof leaks will appear as a hole in PVC foil and water infiltrates into heat insulation. Humid heat insulation has changed heat capacity than dry one. Difference can be seen when air temperature is changing like sunrise or sunset. Thus, roof leaks are spotted at this daytime by thermography.

Example of roof leak is seen on figure 5 in red ellipse. Roof leaks are detected by different radiant heat than other part of roof surface. Area of different radiant heat on TIR ortomosaic is compared with RGB ortomosaic. Radiant heat can cause air conditioning, open roof window, puddles of water or trash. Also change of colour of PVC foils cause change of radiant heat, it is important task to distinguish between roof leak and change of colour on TIR ortomosaic. When change of colour on RGB ortomosaic is not corresponding with shape in TIR ortomosaic, roof leak is confirmed if RGB ortomosaic have same change of colour, as it is seen on figure 5. Red and purple ellipse have same change of colour on RGB ortomosaic, but radiant heat on TIR ortomosaic is different, it is caused by something else than change of colour. The only explanation is humid heat insulation under PVC foil. Green ellipse shows radiant heat caused by shadow cast. Roof under shadow cast is less heated than open air.

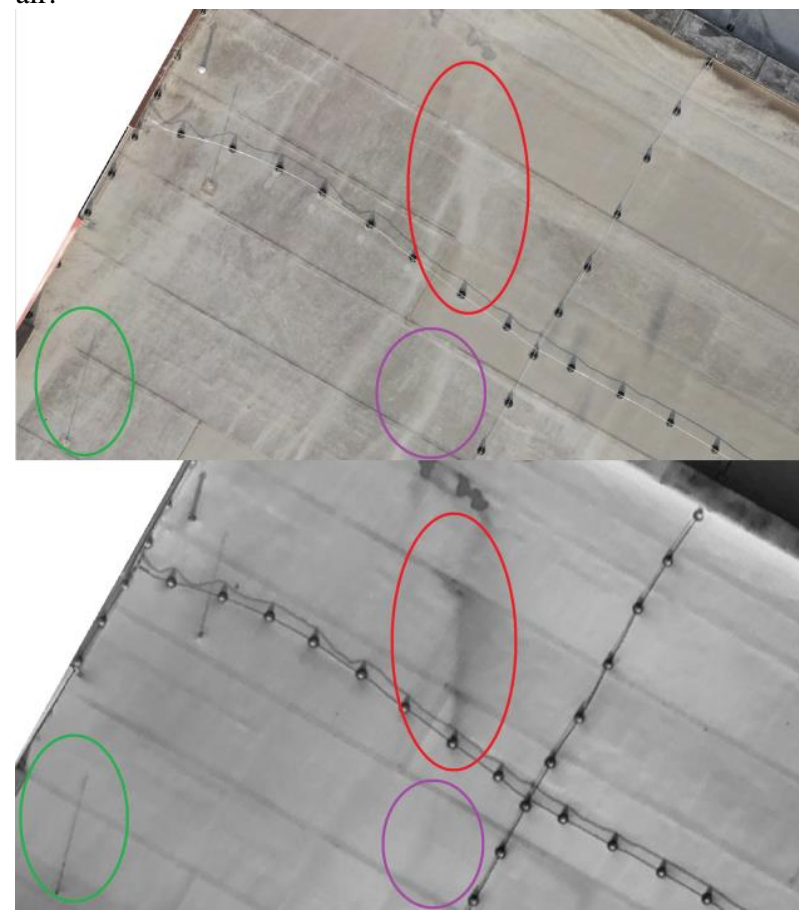

Figure 5. Roof detail, RGB (up), and TIR (down) ortofoto,

green ellipse (shadow), red ellipse (leakage) and purple (colorized roof)

Nowadays the detection of roof leaks is done manually by comparison RGB and TIR ortomosaic. Results of automation is seen in figure 6. Process includes RGB ortomosaic segmentation and classification to PVC foil, roof windows, footpath, and other accessories. Next step is segmentation TIR ortomosaic and classification by radiant heat only on classified
PVC foil areas. Process is still being developed because solution doesn't include PVC foil area with changing color.

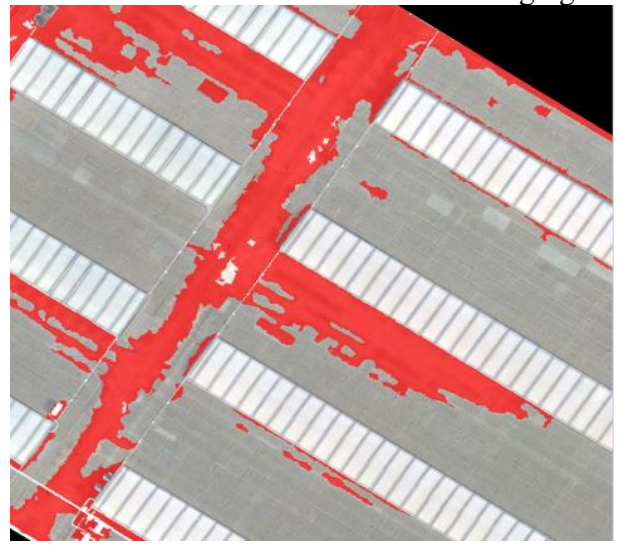

Figure 6. Automatic roof leak detection

\section{BIM IMPLEMENTATION}

Building information models are data managers throughout the life cycle of buildings. The appropriate storage of information is needed not only during construction, but also during the operation of the construction. During the life cycle of a building, a large part of the costs relates to the maintenance of technical installations that are not visible to the naked eye. Part of the costs can be significantly reduced by the documentation used and better coordination and cooperation by using the whole construction model.

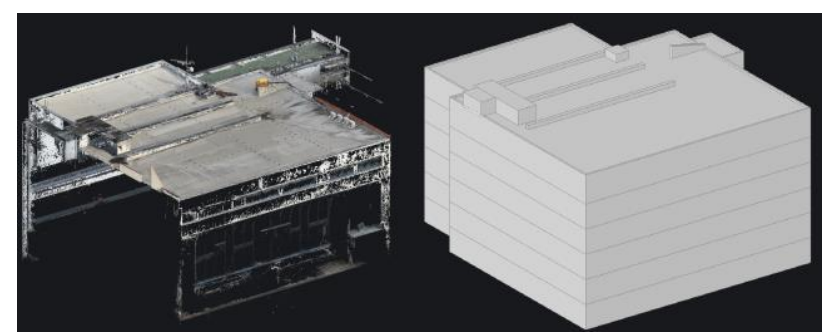

Figure 7. BIM modelling

BIM model is also creatable from dense point cloud by RGB images. Process of modelling is the same as data from TLS scanner. SfM photogrammetry can be considered geometrically equivalent. (Peña-Villasenín et al., 2018). For example, in this paper GCP wasn't used, only RTK module was used for position of images. Accuracy of dense point cloud from SfM wasn't determined because it isn't necessary for the purpose of this paper.

\subsection{Revision cloud}

The Simplest way to add roof leakage to BIM building management process is its representation as revision cloud on 2D plans. Revision cloud represents area of roof leakage, its storage date, and other comments.

\subsection{Building Element}

Roof leak is presented as general building element and it is child of roof element. Position and area are main properties of roof leaks. Repairman must know, where heat insulation must be changed, and PVC foil cobbled together. Category properties divides roof leaks on repair (high moisture) and monitor (low moisture. Date properties keep time of capturing date for re- 
inspection of roof. Repair properties inform about data repairmen and company which made it.

Figure 8. Roof leaks in BIM environment

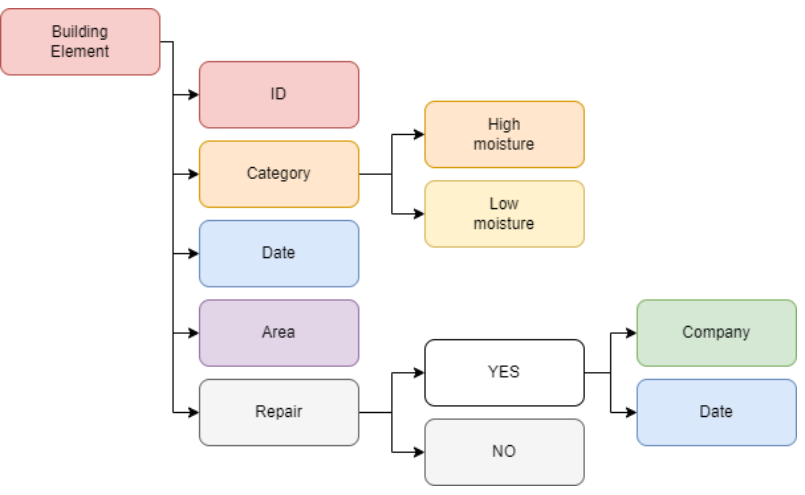

Figure 8. Leak properties

\subsection{BIM + GIS}

The future is the interconnection of BIM and GIS, combining the benefits of both environments robust managing data and quick problem solving.

Data from roof leaking detection like ortomosaic is better to visualize in GIS environment, 2D object is always better to visualize in 2D environment. Connection between BIM and GIS in roof leak detection example is through roof. BIM roof element contain itself hyperlink into GIS environment as it is seen in figure 9. GIS environment is not necessary to link other BIM element because GIS data contain only data for roof. Roof structure plan in GIS environments helps to identify risks of roof leakage. Water can leak into building and damage highcost accessories. Roof leaks have the same properties like in BIM environment, so roof leaks properties can be connected through BIM and GIS environment.

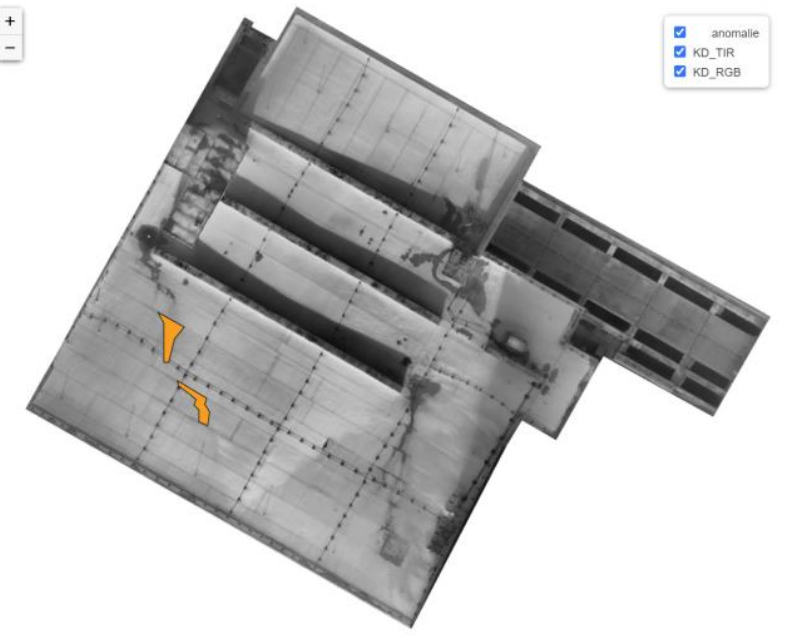

Figure 9. GIS environment

\section{CONCLUSION}

The paper investigated a method for roof leak detection and its implementation into BIM. The Process has 4 main steps: 1) data collection; 2) reconstruction of mesh model and ortomosaic; 3) roof leak detection; 4) implementation results into BIM. The proposed method of processing of TIR images is based on found references and previous experience. The method presents robust solution for most horizontal roofs. Impementation results into BIM is on theoretical level and its present recommendation of results by roof leak detection to achieve cooperation between builder and management.

Image data was captured by DJI Mavic 2 Enterprice Advence Dual, UAV include RGB and thermo camera and it is able to shoot image simultaneously. Data was processed by Structure from Motion method in Agisoft Metashape software to RGB and TIR ortomosaic. Roof leaks were sought by moisture heat insulation, which has bigger heat capacity than a dry one. Founded roof leaks were implemented into BIM by a different way, the most useful variant is integration BIM and GIS environment. Results from roof leak detection like ortomosaic is better to visualize in $2 \mathrm{D}$ environment, BIM is presented by floor plans to overlap ortomosaic.

In the future it is planned to develop web browser application with integration BIM and GIS environment and provide complex comprehensive roof leaks management.

\section{ACKNOWLEDGEMENTS}

This work was supported by the Grant Agency of the Czech Technical University in Prague, grant No. SGS21/054/OHK1/1T/11.

\section{REFERENCES}

Adamopoulos E, Volinia M, Girotto M, Rinaudo F., 2020: Three-Dimensional Thermal Mapping from IRT Images for Rapid Architectural Heritage NDT, Buildings, 10(10):187. https://doi.org/10.3390/buildings10100187

Antón García, D. y Amaro Mellado, J.L., 2021: Engineering graphics for thermal assessment: 3D thermal data visualisation based on infrared thermography, GIS and 3D point cloud processing software. Symmetry, 13 (2(335))

https://doi.org/10.3390/sym13020335

Daffara C, Muradore R, Piccinelli N, Gaburro N, de Rubeis T, Ambrosini D., 2020: A Cost-Effective System for Aerial 3D Thermography of Buildings. Journal of Imaging. 6(8):76. https://doi.org/10.3390/jimaging6080076

Dlesk A, Vach K, Pavelka K. 2021: Transformations in the Photogrammetric Co-Processing of Thermal Infrared Images and RGB Images, Sensors. 2021; 21(15):5061. https://doi.org/10.3390/s21155061

Dlesk, A., Vach, K., and Holubec, P., 2018: USAGE OF PHOTOGRAMMETRIC PROCESSING OF THERMAL IMAGES FOR CIVIL ENGINEERS, Int. Arch. Photogramm. Remote Sens. Spatial Inf. Sci., XLII-5, 99-103, https://doi.org/10.5194/isprs-archives-XLII-5-99-2018

Ham, Y., \& Golparvar-Fard, M., 2015: Reflecting the As-is Building Condition in Energy Analysis. Journal of Construction Engineering and Project Management, 5(4), 16-22. https://doi.org/10.6106/JCEPM.2015.5.4.016

Jairo Acuña Paz y Miño, Nicolas Duport, Benoit Beckers, 2021: Pixel-by-pixel rectification of urban perspective thermography, Remote Sensing of Environment, Volume 266, 112689,

https://doi.org/10.1016/j.rse.2021.112689 
Karam Kim, Hyunjoo Kim, Wooyoung Kim, Changduk Kim, Jaeyo Kim, Jungho Yu, 2018: Integration of ifc objects and facility management work information using Semantic Web, Automation in Construction, Volume 87, 173-187, ISSN 09265805, https://doi.org/10.1016/j.autcon.2017.12.019.

S. Lagüela, L. Díaz-Vilariño, J. Armesto, P. Arias, 2014: Nondestructive approach for the generation and thermal characterization of an as-built BIM. Construction and Building Materials, Volume 51, 55-61,

https://doi.org/10.1016/j.conbuildmat.2013.11.021

S. Lagüela, L. Díaz-Vilariño, J. Martínez, J. Armesto, 2013: Automatic thermographic and RGB texture of as-built BIM for energy rehabilitation purposes, Automation in Construction, Volume 31, 230-240,

https://doi.org/10.1016/j.autcon.2012.12.013

S. Lagüela, L. Díaz-Vilariño, J. Armesto, P. Arias, 2014: Thermographic 3D models as the foundation for Building Information Models. 11th International Conference on Quantitative InfraRed Thermography http://dx.doi.org/10.21611/qirt.2012.180

Macher, Hélène \& Boudhaim, Marouane \& Grussenmeyer, Pierre \& Siroux, M. \& Landes, Tania., 2019: Combination of thermal and geometric information for BIM enrichment. Remote Sensing and Spatial Information Sciences. XLII-2/W15. 719725. 10.5194/isprs-archives-XLII-2-W15-719-2019

Mitchell, J., \& Schevers, H., 2006: Building information modelling for FM using IFC. Proc., CRC Construction Innovation

Norhan Bayomi, Shreshth Nagpal, Tarek Rakha, John E. Fernandez, 2021: Building envelope modeling calibration using aerial thermography, Energy and Buildings, Volume 233, 110648, ISSN 0378-7788,

https://doi.org/10.1016/j.enbuild.2020.110648.

Previtali, M., Barazzetti, L., Brumana, R., \& Roncoroni, F., 2013: Thermographic analysis from UAV platforms for energy efficiency retrofit applications. Journal of Mobile Multimedia, 066-082

Solla, M.; Gonçalves, L.M.S.; Gonçalves, G.; Francisco, C.; Puente, I.; Providência, P.; Gaspar, F.; Rodrigues, H., 2020: A Building Information Modeling Approach to Integrate Geomatic Data for the Documentation and Preservation of Cultural Heritage. Remote Sens. , 12, 4028. https://doi.org/10.3390/rs12244028

Tarek Rakha, Yasser El Masri, Kaiwen Chen, Eleanna Panagoulia, Pieter De Wilde, 2021: Building envelope anomaly characterization and simulation using drone time-lapse thermography, Energy and Buildings, 111754, ISSN 03787788, https://doi.org/10.1016/j.enbuild.2021.111754

Worawan Natephra, Ali Motamedi, Nobuyoshi Yabuki, Tomohiro Fukuda, 2017: Integrating 4D thermal information with BIM for building envelope thermal performance analysis and thermal comfort evaluation in naturally ventilated environments, Building and Environment, Volume 124, 194208, https://doi.org/10.1016/j.buildenv.2017.08.004
Yishuo Huang, Paul Shih, Keng-Tsang Hsu, Chih-Hung Chiang, 2020: To identify the defects illustrated on building facades by employing infrared thermography under shadow, NDT \& E International, Volume 111, 102240, ISSN 09638695, https://doi.org/10.1016/j.ndteint.2020.102240

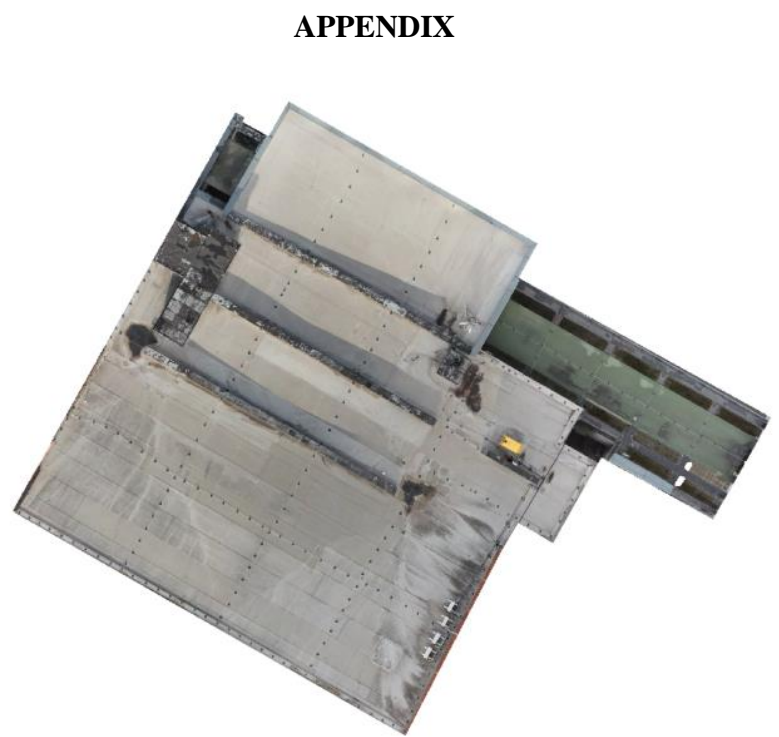

Figure 10. RGB Ortomosaic of testing object

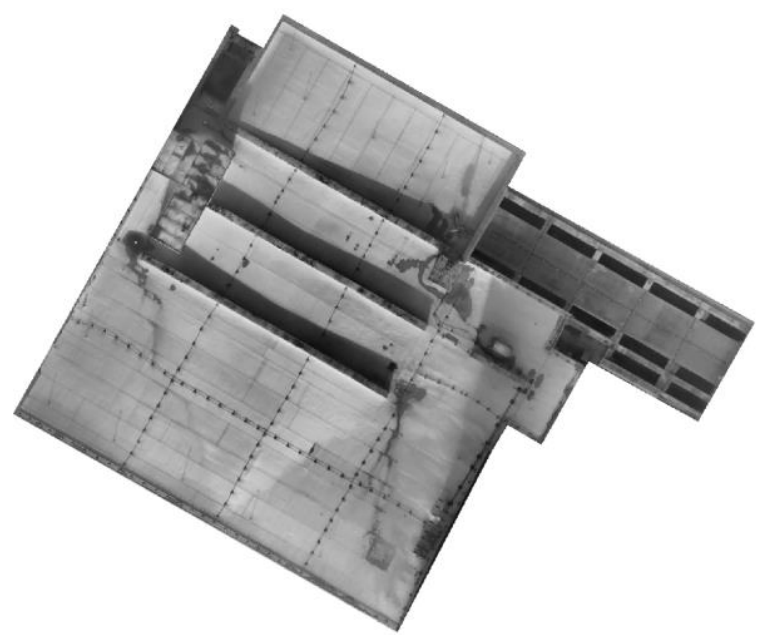

Figure 11. TIR Ortomosaic of testing object 